\title{
October 1942: a strange epidemic paralysis in Saval, Verona, Italy. Revision and diagnosis 50 years later of tri-ortho-cresyl phosphate poisoning
}

\author{
Luigi Tosi, Carlo Righetti, Luciano Adami, Giampietro Zanette
}

\begin{abstract}
In the autumn of 1942 a strange epidemic paralysis started in Saval, at that time a country area but now part of the city of Verona. The epidemic went on for several months and affected 41 people, all working as owners or labourers on the same farm. Some of the farm animals (chickens, horses, cattle, pigs) also became ill. About 20 patients were admitted to the nearby city hospital. The outbreak was diagnosed as polyneuritis with a probable viral cause. Fifty years later, seven people with sequelae of the disease were examined. The most severe cases present a spastic paraplegia and lower leg muscle atrophy without sensory impairment, resembling an amyotrophic lateral sclerosis "frozen" for 50 years. The clinical syndrome can now be attributed confidently to organophosphate induced delayed polyneuropathy. All the epidemiological data obtained from the survivors were evaluated and a careful review of the literature was made. Contamination of the ground from a rubbish dump near the farmyard would explain the epidemiology of the Saval outbreak.
\end{abstract}

(F Neurol Neurosurg Psychiatry 1994;57:810-813)

Some years ago one of us (LT) examined a patient with a remarkable walk, with scissoring with steppage; the knee jerks were exaggerated, ankle jerks were absent, the lower leg muscles were atrophic, and there was no sensory impairment. The patient said that he had been in this condition since late 1942, when he was affected by a form of paralysis, like many other people working on a farm in Saval. At that time this was a country area but is now part of the city of Verona. The story seemed odd, but was familiar to one of us (LA): since his early childhood, he had often heard his father, the owner of an adjacent farm, tell the story of "the cripples of Saval". We recently had the opportunity to re-examine the patient and his sister, who told the same story and had a similar disability, and we decided to attempt a reconstruction of the event.

The father of LA was able to give some very interesting information. The outbreak became manifest in the late autumn of 1942 and went on for several months. People working on the adjacent farm developed a strange walk and had to go to hospital. The owners, who were the earliest and worst affected, still live in the same house and could easily be contacted. The newspaper reported the event.

The outbreak was actually discussed in a meeting of the city Medical Society, extensively reported in the local paper (L'Arena di Verona, 20 March 1943). Other information of interest was provided mainly by the present owner of the farm, an alert and cooperative 78 year old man, and by other patients. The following points are of greatest epidemiological interest:

(1) The outbreak became manifest in October 1942 and finished in June 1943, having affected 41 people.

(2) The illness consisted of a form of paralysis, starting with cramping muscular pain in the calf. This was followed by muscular weakness, which worsened for some weeks before becoming stationary and then regressing slowly for many months. The evolution in time was essentially uniform but the severity was variable. There was neither associated fever nor deterioration of the general condition. The members of the owner's family and the resident labourers were affected earliest and most heavily. Part time workers or fairly regular visitors were affected later and less severely.

(3) The present owner, at that time a 28 year old man, became ill 20 days after returning home from military service.

(4) Only one person who was certainly never at the farm became ill. This was a woman whose husband had brought two large pumpkins home from the farm.

(5) Animals also became ill, but not all in the same way. Chickens were most evidently affected, horses, pigs and cattle were also involved, whereas rabbits and a dog were unaffected. A blackbird in a cage was evidently ill. In the lecture at the Medical Society the differential diagnosis was narrowed to "the possibility that a neurotropic virus may be the agent of the disease, probably transmitted by an animal parasite".

\section{CASE REPORTS}

During the course of the study seven living victims were interviewed and examined. All became ill while working on the farm and all recalled many other victims who had subsequently died, about whom they were able to give information. All were elderly people with other illnesses, but we concentrated only on pertinent neurological findings. The final evaluation was carried out in December 1992. 
CASE 1

A 78 year old man, who is the present owner of the farm, was the young man reported in the paper who became ill 20 days after returning home from military service, when the other members of his family were already affected. Early in December 1942, he felt a cramp-like contracture in his calf. This subsided in two days, with the onset of increasing weakness; walking was at first possible with steppage and then only with the support of a chair. Within two weeks he was compelled to stay in bed most of the time, and even turning was difficult. Sometimes he was helped to sit at table (his appetite remained very good) but had to be spoon fed, having lost the strength in his hands. He was admitted to hospital and stayed from 3 March to 5 May 1943. Neurological examination showed bilateral foot and hand drop and atrophy of the distal muscles of his legs and hands. Knee jerks were hyperactive and ankle jerks were absent. No sensory impairment, bladder dysfunction, or cranial nerve deficits were present. Examination showed the CSF to be normal. Diagnosis at discharge was polyneuritis. In the subsequent months, the strength in his hands improved, the patient could grasp a stick and at the end of September he was able to walk with strong support. A current neurological examination showed that walking is possible only with the support of two crutches; walking movements are initiated from the hips, which are alternately pushed forward by torso rotation and circumduction, the knees are hyperextended, and there is bilateral foot drop. Knee jerks are hyperactive, ankle jerks are absent, and plantar responses are unobtainable. Considerable atrophy of distal muscle groups in the lower extremities is present, associated with a severe spasticity and sustained clonus of the proximal muscle groups. Flexion and extension of the foot is weak, whereas flexion and extension of knee and hip are stronger but disturbed by spasticity. Muscle strength and reflexes in the upper extremities are normal, despite a slight wasting of the interossei muscles. No fasciculations are present. Sensitivity to pinprick, light touch and position sense of the toes is intact, and sensitivity to vibration is decreased. For many years the patient could contribute to farm work only through sedentary effort (fruit and vegetable selection, refuse sorting).

CASE 2

The 80 year old wife of the owner was his girlfriend at the time of the outbreak. When the family became ill she often remained at the farm to help and, in February 1943, moved there permanently. She became ill on 20 March, with calf muscle cramps and the sensation of walking "with legs in the water, against the stream". The course of the disease and present disability are similar to those of her husband. She walks now at home with bilateral support and can perform most of the housework. They married after the end of the war and had a child.
CASE 3

The 82 year old sister of the owner became ill in November 1942. She was admitted to the city hospital on 9 December with the same symptoms, worsening in the first three weeks until her condition became stable with paresis of the legs and hands. She was able at all times to walk with sticks and to feed herself. Her CSF was normal. After discharge on 26 January 1943, slow recovery continued for two years. She could walk almost normally and work outside. Neurological examination now shows a slight scissoring walk, hyperactive knee and ankle jerks, and extensor plantar responses. The sensitivity to pinprink, light touch, and vibration is normal.

\section{CASE 4}

This 62 year old man was the first patient seen. Then aged 13, he worked with his sister as a domestic servant at the farm. He became ill in December, with a similar evolution and disability to case 1 . More than a year later he was able to walk again with support. He walks now with marked scissoring and steppage; his ankles are so weak that he runs the risk of falling if unsupported. Knee jerks are hyperactive and ankle jerks are absent. There is a pronounced atrophy of the distal muscles of the legs, which are not suitable for a conduction velocity study. No sensory deficits are present. He can carry out most farm work, except tractor driving.

\section{CASE 5}

The 68 year old sister of our first patient became ill at the age of 17 in early November 1942, developing moderate paraparesis with foot drop in the first three weeks. After returning home she experienced slow improvement for some months. In May 1943, she returned to the farm and worked for 20 days. Her condition worsened again until she could no longer walk or feed herself. Returning home again, she improved slowly and, at the end of the year, was able to walk with the aid of sticks. Neurological examination now shows a scissoring walk, hyperactive tendon jerks at the legs with clonus of the ankle, extensor response, and withdrawal to stroking of the sole. Sensation is intact. She can walk at home with bilateral support or a walking frame and perform some housework.

CASE 6

This 65 year old man was a 16 year old foundry worker when he became ill. Like other members of his family, he sometimes worked on the neighbouring farm in exchange for meals and produce. In February 1943 he began to walk with evident steppage and stopped working on the farm but continued in the foundry. After some months he recovered his strength and walked almost normally. $\mathrm{He}$ never experienced symptoms in his hands. $\mathrm{He}$ walks now with light steppage, normally on tiptoe but not on the heel. Dorsiflexion is possible for the big toe but not for the whole foot. Knee jerks are hyperactive and ankle jerks are 
normal. There is no sensory impairment. The father and one brother had the same course.

CASE 7

In May 1943, at the end of the school year, this man, now 63 years old, worked for some days on the farm and, after 20 days, began to walk with steppage. This improved in the subsequent months and he regained normal function of his legs. Dorsiflexion of the foot is still impossible, this being the only neurological sequel.

In summary, we have seen seven subjects with sequelae of an epidemic paralysis affecting many people who worked on a farm 50 years ago. Five have spasticity associated with residual distal muscular atrophy, two only minor distal peripheral deficit. Severe spasticity is associated with peripheral damage in those who lived permanently on the farm, whereas others who worked part time on the farm or were occasional visitors have moderate peripheral sequelae. The total incidence is hard to evaluate. Many of the people affected were able to get about and continued their work, without medical consultation, compelled by the hard necessities of wartime. As far as we could reconstruct, 41 people were definitely affected. At that time a diagnosis of polyneuritis was made. Subsequently, amyotrophic lateral sclerosis or multiple sclerosis were suspected in some cases but not confirmed.

\section{Discussion}

The clinical picture resembles the detailed description of tri-ortho-cresyl phosphate (TOCP) poisoning by Scheid in $1963 .{ }^{1}$ Transient mild gastrointestinal symptoms may appear on the first day. Neurological symptoms appear 10-20 days after poisoning, with a cramping muscular pain at the calf. The motor deficit develops over some weeks, attains a maximum intensity, and then regresses slowly over a period of many months. There is no persistent sensory impairment. The conserved knee jerk is remarkable from the outset, but "in some cases spastic symptoms may appear ... the

Major outbreaks of TOCP poisoning

\begin{tabular}{|c|c|c|c|}
\hline Years & Place & No of cases & Vehicles of TOCP \\
\hline $\begin{array}{l}1898-1900 \\
1900-28 \\
1930-1 \\
1930-5 \\
1938 \\
1940 \\
1940-6 \\
1942-3 \\
1945 \\
1955 \\
1956 \\
1959 \\
1960 \\
1962 \\
1966 \\
1967 \\
1971-2 \\
1977-8\end{array}$ & $\begin{array}{l}\text { France } \\
\text { Europe } \\
\text { USA } \\
\text { Europe } \\
\text { Durban-1 } \\
\text { Basel (Switzerland) } \\
\text { Germany } \\
\text { Verona (Italy) } \\
\text { Liverpool (United Kingdom) } \\
\text { Durban-2 } \\
\text { Japan } \\
\text { Morocco } \\
\text { Bombay (India) } \\
\text { West Bengal } \\
\text { Romania } \\
\text { Fiji } \\
\text { Vietnam } \\
\text { Sri Lanka }\end{array}$ & $\begin{array}{l}6 \\
43 \\
30-50000 \\
\text { hundreds } \\
68 \\
80 \\
\text { hundreds } \\
41 \\
17 \\
11 \\
6 \\
10000 \\
58 \\
400 \\
12 \\
56 \\
15-20 \\
20\end{array}$ & 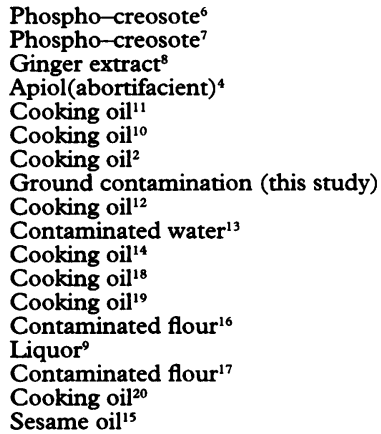 \\
\hline
\end{tabular}

Modified from Morgan ${ }^{8}$ and Inoue et al. ${ }^{5}$ more the polyneuritis regresses, the more marked the spasticity appears." Animals are variously affected. This exhaustive description $^{1}$ derives from the direct experience of about 100 cases of TOCP poisoning due to adulterated cooking oil in wartime Germany. ${ }^{2}$ The similar clinical course of the Saval outbreak necessarily leads to the same diagnosis. The selective involvement of the farm animals, according to the results of experimental poisoning, ${ }^{3}$ removes any doubt. There seem to be no other known causes for an outbreak of human polyneuropathy selectively involving animals and resulting in spasticity.

\section{EPIDEMIOLOGY}

TOCP poisoning has occurred throughout the world. The table lists the major outbreaks. The chemical found access to the human organism in different and sometimes unexpected ways.

(1) As a drug: phospho-creosote in the treatment of pulmonary tuberculosis, ${ }^{6}$ Apiol as an abortifacent. ${ }^{7}$

(2) As alchoholic Jamaica ginger extract, or "Jake", adulterated in defiance of prohibition, ${ }^{8}$ or as a liquor. ${ }^{9}$

(3) Because of a mistake by a Swiss military cook, who used machine gun lubricant as cooking oil. ${ }^{10}$

(4) Owing to the use as food containers of drums previously used for storing TOCP or mineral oil containing TOCP. ${ }^{11-15}$

(5) Owing to contamination of flour in the sacking material during shipping. ${ }^{16} 17$

(6) Owing to adulteration of cooking oil with engine oils of military origin. ${ }^{2}{ }^{18-20}$

None of these mechanisms can convincingly explain the outbreak at Saval. We first considered the "German model" of poisoning through adulteration of cooking oil. This implies that the members of a family would become ill at the same time, whereas several families in the surrounding area would become ill at different times, all having bought the adulterated oil from the same supplier. The same occurred in the outbreaks due to accidental flour contamination (West Bengal, Fiji). In Saval, oil and flour were bought from local suppliers and no other families were affected in the area. Moreover, humans and animals on the farm were affected at very different times. Subsequently we took into consideration the "Durban-2 model" of poisoning through food or fluid contamination from containers previously used for storing TOCP or mineral oils containing TOCP. Obviously, one household or farm alone may be involved in this case, but humans and small animals or poultry are affected simultaneously for a brief period. The farm in Saval had its own traditional food and fluid containers and never had to use occasional containers, as far as we could ascertain from careful questioning of the owners. The extensive, persistent involvement of many large animals like horses, cattle, and pigs, another unique feature of this outbreak, is hardly attributable to a contamination of oil, flour, or any other human food adulterated or 
stored in contaminated containers. Moreover, the attribution of the outbreak to any of the known causes would not explain the consistent report that a woman who was moderately affected was not known to have had any contact with the farm other than eating pumpkins brought home by her husband. Unlike other outbreaks, the onset at Saval was gradual, without involvement of many people at any one time. There were no initial gastric symptoms at all. The environment remained toxic for people and animals for many months. Many data suggest a close connection between the time of stay on the farm-with board and lodging - and the severity of the neurological damage, as if multiple low doses had been ingested, producing a cumulative effect. Owners and servants were affected first, and more severely than part time workers or regular visitors. In case 5, improvement occurred in a servant who returned home, followed by a relapse with severe and permanent sequelae when the subject returned to the farm four months later. Part time workers and visitors (cases 6 and 7) were less severely affected, always able to walk and feed themselves, and today they show moderate sequelae that allow a nearly normal life. This was the case for most of the 41 people affected, as far as we were able to reconstruct their histories. By comparison with other epidemics, this outbreak is more subtle, protracted, and closely related to the duration of stay on the farm in terms of severity. In at least one case, the poison had been transmitted through an item of farm produce. Many epidemiological features are different from those of other TOCP outbreaks and demand a different explanation.

In the search for a convincing mechanism, it seemed important to us that at that time refuse recycling was a secondary farm activity. Rags, waste paper, glass, and metals were collected every evening from the surrounding area and brought to the farm for sorting. In particular, tins and drums were emptied out and pressed for transport to a foundry. Residual organic materials were heaped up and turned into manure. Within a radius of one mile were a large military lorry depot and an airport. Tins and drums with residual military engine oil containing TOCP may have reached the farm and been emptied for recycling, leading to manure and ground contamination and consequently to contamination of animal fodder and of vegetables lying on the surrounding ground. Pumpkins are particularly likely to be contaminated because they are usually grown near compost heaps. The repeated emptying of drums for recycling may explain the protracted toxicity of the environ- ment for humans and animals. Only in some such way can the course of events of which we learned be explained. The hypothesis of an absorption of TOCP in plant tissue has also been considered. The major objection is that TOCP, highly soluble in organic solvents and vegetable oils, has a very low water solubility. Physicochemical properties of the soil and capillarity could favour absorption. The Science Information Service of Glaxo-Verona has carried out a search in various database sources on ecotoxicity of TOCP. A few studies on air and water pollution were found, but none on absorption from soil by plants. There is no experimental evidence to confirm or disprove the hypothesis. The outbreak of Saval ought to be included in the table of major TOCP poisonings, with the peculiarity of a probable ground contamination as the vehicle of TOCP.

We thank the patients for their collaboration, Glaxo-Verona for the bibliographical search, and Mr Peter Mead for improving the English of the manuscript.

1 Scheid W. Lehrbuch der Neurologie. Die polyneuritischen Erkrankungen. Stuttgart: Georg Thieme Verlag, 1963: 615-41.

2 Scheid $W$. Ueber die Schaedigungen durch Triorthokresylphosphat. Nervenarzt 1947;18:56-66.

3 Davis CS, Richardson RJ. Organophosphorous compounds. In: Spencer PS, Schaumburg $\mathrm{HH}$, eds. Experimental and clinical neurotoxicology. Baltimore: Williams and Williams, 1980:527-44

4 Ter Braak JW, Carrillo R. Polyneuritis nach Gebrauch eines Abortivums (Tri-orto-kresylphosphat-Vergiftung). Disch Z Nervenheilk 1932;125:86-116.

5 Inoue N, Fujishiro K, Mori K, Matsuoka M. Triotho-cresyl phosphate poisoning. A review of human cases. Univ phosphate poisoning. A review of human
Occup Environ Health (fpn) 1988;10:433-42.

6 Lorot C. Le combinations de la creosote dans le traitment de la tuberculose pulmonaire. These, Paris: 1899: (Cited by Roger H, Recordier M, 1934.

7 Roger H, Recordier $M$. Le polyneurites phosphocrèosotiques. Ann Med 1934;35:44-63.

8 Morgan JP. The Jamaica ginger paralysis. FAMA 1982; 248:1864-7.

9 Vasilescu C, Florescu A. Clinical and neurophysiological study of neuropathy after organophosphorus compounds poisoning. Arch Toxicol 1980;43:305-15.

10 Staehlin R. Ueber Triortocresylphosphatvergiftungen. Schweiz med Wochenschr 1941;16:1-9.

11 Sampson BF. The strange Durban epidemic of 1937. S Afr Med f 1942;16:1-9.

12 Hotston RD. Outbreak of polyneuritis due to orthotricresyl phosphate poisoning. Lancet 1946;1:207.

13 Susser M, Stein Z. An outbreak of tri-ortho-cresyl phosphate (TOCP) poisoning in Durban. $\mathrm{Br} \mathcal{F}$ Ind Med 1957;14:111-20.

14 Kaneko Z, Mizuno K, Sugimura S, et al. Polyneuropathy due to triorthocresyl phosphate. Sogo Rinsho 1958;7: 1057-68. (In Japanese). (Cited by Inoue et al 1988..$^{5}$ )

15 Senanayake N. Tri-cresyl phosphate neuropathy in Sri Lanka. A clinical and neurophysiological study with a three years follow-up. $¥$ Neurol Neurosurg Psychiatry 1981;44:775-80.

16 Sarkar JK. Outbreaks of paralytic disease in West Bengal due to Tricresyl phosphate poisoning. F Indian Med Assoc 1974;63:359-61.

17 Sorokin M. Orthocresyl phosphate neuropathy. Report of an outbreak in Fiji. Med $¥$ Aust 1969;1:506-8.

18 Smith HV, Spalding JK. Outbreak of paralysis in Morocco due to triortho-cresyl phosphate poisoning. Lancet due to triortho-cr

19 Vora DD, Dastur DK, Braganca MB. Toxic polyneuritis in Bombay due to ortho-cresyl phosphate poisoning. $\mathcal{f}$ Neurol Neurosurg Psychiatry 1962;25:234-42.

20 Denis DT. Jakewalk in Vietnam. Ann Intern Med 1977; 86:665-6. 